\title{
Novas dinâmicas culturais: tensão e vitalidade nas cidades
}

\author{
Nuevas dinámicas culturales: tensión y vitalidad en las ciudades
}

New cultural dynamics: tension and vitality in the cities

\author{
Rachel Gadelha'
}

Palavras chave:

Produção cultural

Gestão cultural

Cultura e cidade

Institucionalidade da cultura

Dinâmicas culturais

\section{Resumo:}

Este trabalho pretende trazer elementos para a reflexão sobre as dinâmicas culturais contemporâneas, abordando algumas mudanças que estão em curso e os desafios que estão postos para os agentes culturais no âmbito das cidades e suas repercussões em uma nova institucionalidade da cultura. Para tanto, faremos um breve histórico das políticas culturais recentes no Brasil, de forma a facilitar a compreensão da conjuntura atual e proporcionar uma visão mais ampliada do campo cultural contemporâneo e de seus distintos agentes, entendendo-o como resultante, também, de um regime de valores e discursos com forte vinculação ao contexto social e político cultural do Brasil nas últimas décadas. Instiga-nos a identificação de novas dinâmicas da cultura e de movimentos de criação emergentes nas cidades, as questões que se configuram hoje e os desafios que estas impõem aos gestores culturais e aos demais agentes do campo; assim como a investigação de como esses novos fluxos se relacionam e afetam uma nova institucionalidade cultural. 


\section{Resumen:}

Este trabajo pretende traer elementos para la reflexión sobre las dinámicas culturales contemporáneas, abordando algunos cambios que están en curso y los desafíos que están puestos para los agentes culturales en el ámbito de las ciudades y sus repercusiones en una nueva institucionalidad de la cultura. Para ello, haremos un breve histórico de las políticas culturales recientes en Brasil, con la finalidad de facilitar la comprensión de la coyuntura actual y proporcionar una visión más ampliada del campo cultural contemporáneo y de sus distintos agentes, entendiéndolo como resultante, también, de un régimen de valores y discursos con fuerte vinculación al contexto social y político cultural de Brasil en las últimas décadas. Nos instiga la identificación de nuevas dinámicas de la cultura y de movimientos de creación emergentes en las ciudades, las cuestiones que se configuran hoy y los desafíos que éstas imponen a los gestores culturales ya los demás agentes del campo; así como la investigación de cómo estos nuevos flujos se relacionan y afectan a una nueva institucionalidad cultural.

\section{Palabras clave:}

Producción cultural

Gestión cultural

Cultura y ciudad

Institucionalidad de la cultura

Dinámicas culturales

\section{Keywords:}

Cultural production

Cultural management

Culture and the city

Institutionality of culture

Cultural dynamics

\section{Abstract:}

This paper intends to bring elements for the reflection on contemporary cultural dynamics, addressing some changes that are underway and the challenges that cultural agents have to deal with within the cities scope and their repercussions on a new institutionality of culture. Therefore, we will give a brief history of recent cultural policies in Brazil, in order to facilitate understanding of the current conjuncture and provide a broader view of the contemporary cultural field and its different agents, understanding it also as a result of a regime of values and discourses with strong ties to the social and political cultural context of Brazil in the last decades. It instigates the identification of new cultural dynamics and emerging creative movements in the cities, the issues that are configured today and the challenges they impose on cultural managers and other actors in the field; as well as the investigation of how these new flows interrelate and affect a new cultural institutionality. 


\section{Novas dinâmicas culturais: tensão e vitalidade nas cidades}

\section{Um breve histórico}

A gestão pública da cultura no Brasil é fortemente marcada por uma tradição política paternalista, pela alternância de interesses que oscilam de acordo com distintos governos e por políticas alinhadas com afinidades artísticas pessoais de gestores. Temos em nossa memória a imagem de um Estado que dava um pouco para (quase) todos, comprometendo aqueles que recebiam as benesses com gratidão e silencioso consentimento.

Relações que marcaram a atuação dos agentes no campo cultural, contribuindo para o estabelecimento de práticas amadoras, cenários instáveis e uma condição de submissão ao poder instituído que, de alguma forma, ainda permeiam o imaginário e a vivência dos artistas, gestores e profissionais que se confrontam cotidianamente com crescentes necessidades de empoderamento e autonomia, em paradoxal coexistência com uma forte dependência do Estado, ainda responsável pelas principais fontes de recursos destinados à cultura no Brasil.

As Leis de Incentivo" tiveram o mérito de apresentar aos agentes culturais uma nova possibilidade de financiamento de seus projetos e sinalizar para uma atenuação da relação de dependência direta do Estado, apesar dos recursos continuarem sendo públicos. Estimularam a profissionalização dos agentes da cultura, o surgimento de um incipiente mercado cultural e de uma nova categoria profissional: os produtores culturais. Induziram também uma maior qualificação dos agentes para o ingresso no novo "mercado da cultura", uma vez que tiveram que aprimorar discursos e incorporar técnicas gerenciais na criação de projetos culturais "viáveis e atrativos".

O início do século XXI trouxe significativas mudanças na cultura política do país, com um novo regime de valores que se instaurou no país no Governo Lula (2003 a 2011). Já no discurso de posse de Gilberto Gil"I quando esteve à frente do Ministério da Cultura (MINC), podemos perceber toda a carga simbólica e política que orbitava em torno da Cultura quando afirma que o novo governo representa uma "mudança estratégica e essencial, que mergulhe fundo no corpo e no espírito do país" e continua enfatizando o papel das políticas culturais do governo como "parte do projeto geral de construção de uma nova hegemonia em nosso país... e que deverá permear todo o governo, como uma espécie de argamassa de nosso novo projeto nacional". Neste discurso, Gil afirma que cabe ao Ministério da Cultura corrigir as distorções do mercado e assumir uma postura mais intervencionista. Era a senha para o que estava por vir.

Foi com essa missão ampla e complexa, que o Ministério da Cultura na gestão de Gil e Juca (2003 a 2010) estabeleceu uma importante fase da política cultural com a formulação e execução de diversos programas e projetos, a abertura de diálogos com a sociedade e a inserção da pauta da Cultura brasileira na agenda política do país.

Deu-se também, com mais ênfase, a proposição de outro mecanismo de incentivo à cultura: os editais ${ }^{\prime V}$. Devido a seu poder de capilaridade social e sua esfera de micro atuação, tornaram-se instrumento imprescindível na concepção das novas políticas culturais. Apesar de reconhecermos a validade dessa modalidade de repasse de recursos, não podemos deixar de registrar alguns "efeitos colaterais". Além de gerar uma excessiva dependên- 
cia estatal criando o que podemos chamar de geração de "editais dependentes", foi responsável pela indução de conceitos adotados pelo Estado e absorvidos pelo campo como se fossem inerentes à própria ação cultural contemporânea.

Observou-se, nesse contexto, a ênfase nas políticas para a cultura, em detrimento das políticas para arte e a crescente inserção de conceitos como acessibilidade, inclusão cultural, democratização da cultura, diversidade e pluralidade cultural, dentre outros. Dessa forma, como argumentado por Yúdice, a cultura passou a ser utilizada progressivamente como importante recurso para a obtenção de fins sociopolíticos e econômicos e minimização de problemas sociais, conferindo-Ihe um caráter de cultura utilitária, conforme assinala:

hoje em dia é quase impossível encontrar declarações públicas que não arregimentem a instrumentalização da arte e da cultura... A arte se dobrou inteiramente a um conceito expandido de cultura que pode resolver problemas, inclusive o de criação de empregos. Seu objetivo é auxiliar na redução de despesas e, ao mesmo tempo, ajudar a manter o nível de intervenção estatal para a estabilidade do capitalismo. Uma vez que todos os atores da esfera cultural se prenderam a essa estratégia, a cultura não é mais experimentada, valorizada ou compreendida como transcendente... a arte e a cultura são vistas como fundamentalmente interessadas. (YÚDICE, 2004, p. 27-28)

Para compreender a dimensão e o alcance desse novo regime de valores, podemos nos remeter ao filósofo francês Michel Foucault, que trata das formas de poder não mais como uma concentração de força unidirecional, total e global; mas como um campo reativo e energi- zado, em constante mutação, construído historicamente através de diferentes mecanismos e processos (BARBALHO; BEZERRA; GADELHA, 2014). Segundo Foucault, para se produzir verdades faz-se necessário governar coisas. Coisas que criam sentidos e estabelecem relações entre os homens, afirmando que o que se governa são "os homens em suas relações com outras coisas que são os costumes, os hábitos, as formas de agir ou pensar (...) que o governo diga respeito às coisas entendidas como imbricação de homens e coisas..." (FOUCAULT, 1984, p. 283).

E é sob essa perspectiva de um poder acionado por meio de ideias e políticas que destacamos uma dimensão subjetiva das políticas do Governo Lula. Além de mecanismos concretos de gestão de uma política cultural, muitos dele agora em "cheque" na conjuntura atual, vimos a criação de um conjunto de dispositivos que geraram consensos em toda uma geração de agentes culturais, marcada pela percepção de uma cultura benéfica, totalizante, abrangente e socialmente redentora.

Ainda sem saber como dar conta dessa enorme responsabilidade social, os agentes culturais assistiram mudanças no âmbito da cultura no Brasil. Primeiro deu-se um esvaziamento silencioso e inesperado do prestígio da pauta da Cultura no Governo de Dilma Roussef (2011 a 2016) e posteriormente as disputas políticas no país que ocasionaram o impeachment da presidente, levando a posse de Temerv . Cenários que trouxeram novos desafios aos agentes culturais, assim como a todo o campo da cultura. Em um curto espaço de tempo, vivemos a ameaça da extinção do Ministério da Cultura, a posse de três ministros, escândalos relativos à Pasta em noticiários, suspeições na aplicação da Lei Rouanet e a criação de uma instrução normativaVI para sua utilização. 
Presenciamos também ocupações e atos de resistência por todo o país, debates e mobilizações em torno da cultura, formação de fóruns e associações, e reações da sociedade na defesa da manutenção das conquistas e avanços nas políticas culturais. Reações que também convivem com a apatia de grande parte dos agentes culturais, o desânimo por falta de verbas, a desvalorização da Pasta e o desmantelamento de iniciativas e instituições que pareciam consolidadas.

Muito mais do que falta de recursos, falta visão política e percepção social do valor e relevância da cultura. Há um sentimento generalizado de perplexidade e descrença por parte dos agentes culturais em um presente viável e em um futuro possível. Observa-se também um esgotamento na institucionalidade cultural que já não consegue dar conta das novas dinâmicas e exigências do campo. Na administração pública ainda não conseguimos atingir um padrão eficiente de gestão da cultura e o que é mais grave, não temos sequer consensos mínimos sobre o lugar da centralidade que as políticas culturais deveriam assumir.

Paira uma desconfiança sobre as leis de incentivo que, somada à crise econômica, ameaça a continuidade de projetos que vêm sendo realizados por meio de incentivo fiscal, agravando a precária perspectiva de sustentabilidade ao setor. Os editais não conseguem dar conta da imensa e crescente demanda de artistas e produtores em todo o Brasil e, ainda assim, não conseguem efetuar os devidos repasses financeiros em tempo hábil. Diante dessa realidade, uma quantidade significativa de artistas e produtores se encontra paralisada, como se não houvesse vida possível fora das benesses do recurso público. Além da frustração, há um rancor incontido contra o Estado provedor.
Paralisados, sem o apoio e distantes de um mercado das artes (discriminado, diminuído e desvalorizado), os agentes culturais se veem diante da perplexidade de um novo cenário e com grandes inquietações. Estado, artistas, gestores e sociedade civil parecem não encontrar caminhos que traduzam e atendam às novas necessidades. Em tempos de exacerbação de Direitos Culturais, de incompreensões e acusações mútuas, e de fronteiras ilimitadas com as múltiplas possibilidades das culturas computacionais; a institucionalidade da cultura se vê ameaçada por uma ausência de delicadeza e excessiva rigidez de processos, pelo risco da indução e direcionamento de valores; pela pouca percepção de sua relevância política; por marcos legais inadequados e processos de fiscalização que não acompanham a dinâmica e os fluxos culturais. Urge como diz Certeau, superar os limites repressivos de uma política que "não garante a felicidade nem confere significado às coisas. Que cria ou recusa condições de possibilidades. Interdita ou permite: torna possível ou impossível" (CERTEAU, 2012, p. 214).

Todas essas questões se relacionam, em maior ou menor intensidade, com a institucionalidade ${ }^{\mathrm{VII}}$ da cultura, fazendo deste tema um grande desafio no Brasil contemporâneo, não só pela dificuldade de encontrar padrões de gestão e organização que consigam dar conta de um sistema de signos tão amplo, reativo, mutável como aquele que permeia o campo da cultura e das artes, mas também pelo contexto político, econômico e social em que estão inseridas as políticas de cultura no país.

Segundo Martinell (2017), a própria noção de institucionalidade já traz em si uma resistência à mudança, dificuldade de adaptação ao presente e pouca capacidade de antecipação de futuro. Essa condição se revela em nosso con- 
texto de macro política social e permeia todos os processos da institucionalidade, dificultando a aproximação com a sociedade civil e impedindo a percepção das necessidades, mudanças, desejos, rotas de fuga e formas de resistência em curso no campo cultural.

São inúmeras as questões que estão postas no âmbito da institucionalidade da cultura e todas anunciam, de alguma maneira, as novas dinâmicas culturais e as relações de disputas, tensões e paradoxos que precisam ser enfrentadas hoje pelos gestores culturais na contemporaneidade em seus distintos contextos territoriais.

\section{Novas Dinâmicas Culturais}

Um dos maiores desafios que temos pela frente é a (in)compreensão do lugar da cultura no Brasil, ainda pouco claro para a sociedade em geral, para os políticos e até mesmo para os próprios agentes culturais. A falta de um entendimento mínimo sobre a cultura incide sobre o campo de várias maneiras. Desde a descontinuidade, desarticulação e diversidade das políticas até a falta de clareza sobre seus propósitos e resultados. A ausência de dados e processos avaliativos inviabiliza a geração de indicadores esclarecedores e significativos no âmbito da cultura.

Ao propor uma discussão sobre a ideia da cultura e o valor simbólico de um bem cultural, Teixeira Coelho (2008) direciona o olhar para outro ponto nevrálgico das políticas culturais recentes ao afirmar que a cultura é vista como positiva em si, importante mecanismo de contenção social, de inclusão, cidadania e desenvolvimento, portadora de uma essência que a isenta de avaliações críticas.

Políticas que trouxeram consequências importantes para o campo da cul- tura, conforme apontado por Teixeira Coelho (2008), quando destaca uma espécie de hierarquização de conceitos, onde a arte, em seu caráter transgressor e estético, é posicionada em segundo plano, em comparação ao poder estruturador da cultura. É um desafio para a nova institucionalidade compreender a cultura para além de sua positividade e acolher a arte em seu papel fundamental de negação dessa cultura. Uma arte inútil, sem serventia e principalmente, impossível de ser domesticada é também um desafio para a institucionalidade cultural.

Em tempos de Direitos Culturais, vivemos em um cenário de tensões, polêmicas e debates no campo das liberdades culturais; paradoxalmente, cada vez mais, com menos espaço para o respeito às diferenças e o diálogo. Parece não haver consensos possíveis e vale muito mais afirmar do que buscar entendimento. No centro desse debate muitas vezes está a arte, incômoda e demonizada em seu potencial questionador, como podemos perceber com as polêmicas em torno da Mostra Queermuseu ${ }^{\text {VIII em }}$ Curitiba. Arte que, ainda segundo Teixeira Coelho, é extremamente perigosa por sua capacidade de preencher "todos os espaços vazios de conteúdo e sensibilidade". (COELHO, 2008, p. 105). Arte que divide e estranha; mas também que sensibiliza, aproxima e nos faz reconhecer como semelhantes.

Outro efeito nefasto da percepção positiva da cultura é o caráter messiânico e a ideia de abnegação que é transferido àqueles que trabalham em seu campo, gerando uma espécie de tabu e distanciamento em relação ao mercado, como se a aproximação com este, desmerecesse e desclassificasse um bem cultural e artístico. É preciso criatividade e coragem para investir na formação de um mercado com vistas a minimizar a excessiva dependência do Estado no processo de criação e 
circulação das artes. Além de ampliar mercados, precisamos buscar novas formas de sustentabilidade e desenvolver tecnologias de financiamento e produção cultural colaborativa, criando projetos que façam sentido para as comunidades onde se inserem, onde as pessoas comuns possam se sentir envolvidas de alguma forma. Investir na formação de públicos e consumidores de cultura e desconcentrar a oferta e produção cultural nas cidades. Buscar formas de mobilizar pessoas para projetos que conciliem qualidade estética e liberdade artística. Criar alternativas de subsistência digna para além do Estado.

Atinar para o fato de que nem sempre os processos de democratização do acesso à cultura passam pela gratuidade obrigatória, mas muito mais por fatores relacionados à educação, à oferta de produtos artísticos e culturais continuada, descentralizada, ampla e plural; ou seja, a um valor a esse bem atribuído. É uma conquista a não se perder de vista, fundamental para um cenário de cultura mais favorável e consistente nas próximas gerações.

É preciso ainda (e cada vez mais) não permitir que o Estado recue em suas funções de garantir as políticas e assegurar os direitos culturais, mas também buscar formas de (co)existir para além dele. Romper um ciclo antigo e oscilante de dependência e ressentimentos. Atuar incansável e politicamente, de forma propositiva, afetiva e coletiva. Para isso, Estado e agentes culturais precisam se qualificar, perceber os novos fluxos e acessar outras forças criativas e mobilizadoras.

E aqui consiste um dos maiores desafios de uma nova institucionalidade da cultura: é preciso que o Estado seja permeável, flexível, capaz de acolher críticas e tensionamentos. Perceber mudanças, construir com a sociedade e reconhecer os agentes culturais como companheiros essenciais e inevitáveis nessa jornada. Requer uma nova institucionalidade da cultura, novas percepções e leituras e, sobretudo, muita escuta.

Em primeiro lugar e de forma essencial, é preciso que se abandone uma linguagem unívoca e que se passe a trabalhar com multiplicidade de sistemas que fujam aos imperativos únicos de uma administração central e irredutíveis a uma fórmula global, conforme apregoa Certeau (2012). Há uma ausência de sentidos (tatos, escutas, visões...) que faz com que o Estado se apresente como incapaz de perceber as novas dinâmicas culturais, a pluralidade de poderes e as formações emergentes de sujeitos políticos em distintos contextos territoriais, anunciado também por Lucia Maciel (2017) ao destacar a "pouca porosidade" das instituições para uma nova realidade.

Muito além da aparente desmobilização e desmonte das políticas culturais na contemporaneidade, vislumbramos aqui novas dinâmicas culturais e territoriais e outras possibilidades de existência criativa, surgidas além do Estado e independente de sua tutela direta e ainda assim, em forte relação com ele. Onde tudo parece ruir, surge uma nova força vinda de distintos atores culturais que atuam em forma de redes e localizações incertas, por meio de experimentações e acionamento de micropolíticas em distintos contextos territoriais, desejos, múltiplos recursos e tecnologias computacionais. Diante de um cenário de desconcertos e incertezas, vislumbramos oportunidades, desafios e possibilidades de reinvenções que já estão em curso.

\section{Novas dinâmicas nas Cidades}

Segundo Teixeira Coelho (2008, p. 9), "a cidade é a primeira e decisiva esfera cultural do ser humano". É, portanto, 
o lugar onde a vida acontece, onde construímos nossas sociabilidades; espaço de nossos sonhos, afetos e realizações. É na cidade onde se concentram as necessidades básicas, mas também as energias criadoras, as possibilidades de transformação e reinvenção, as microrrevoluções e inovações. Território de atuação, resistência e criação dos distintos agentes culturais.

E é nesse lócus privilegiado de interação cultural que se dá a reinvenção do nosso cotidiano cultural, em suas diversas dimensões, e as inúmeras conquistas que temos pela frente, conforme enunciado por Coelho (2008, p. 9):

A renovação e expansão dos recursos culturais da cidade; o apoio às instituições culturais centrais, a criação de recursos culturais de porte cotidiano criando uma malha cultural sólida; a definição de modos culturais criativos de relacionamento com os equipamentos e problemas urbanos; o estímulo à cidade culturalmente diversa; a opção pelo desenvolvimento humano ainda mais que pelo desenvolvimento econômico; o cuidado no respeito e na multiplicação dos direitos culturais, renovados com criatividade; o apoio à ideia de uma nova cidade transformada que com seu exemplo possa mover o mundo; a definição do que podem ser os indicadores dessa nova gestão cultural da cidade; a nova institucionalidade da cultura solicitada pelos novos desafios; a sustentabilidade do processo cultural e, finalmente, mas não em último lugar, o papel da sociedade civil no novo arranjo da cultura na cidade que deve tornar realidade uma política cultural de proximidade...

É no âmbito de atuação da sociedade civil que se efetiva a importância dos agentes culturais, que com sua capacidade de mobilização e capilaridade territorial ativam a rede cultural da cidade fazendo pulsar a vida nas diversas localidades do Brasil. São eles, inúmeros e quase invisíveis, que com ou sem a presença do Estado, estimulam os movimentos culturais e a criação artística nos bairros periféricos e pequenos distritos. Em todos os lugares improváveis do Brasil "profundo" criam projetos que afetam as cidades com aproximações sociais e comunitárias e buscam alternativas inovadoras de sustentabilidade e formação de público e mercado. Fazem emergir uma força criativa de baixo para cima que é capaz de afetar o Estado e que vai ao encontro das políticas públicas. Seja no alinhamento ou no enfrentamento.

Nessa perspectiva, ganham uma maior relevância os agentes da cultura nas mais distintas cidades e localidades do país. Conforme apresentado por Alfons Martinelli, os agentes culturais são

atores (individuais, coletivos, institucionais, etc.) que interveem ou podem intervir, ativa ou passivamente, em sentido positivo ou negativo, na articulação das políticas em diferentes estruturas sociais... elemento de dinamismo de um território... fator determinante da consolidação de uma intervenção social, da vida cultural e uma garantia democrática. (MARTINELL, 2017, p. 1)

São esses agentes culturais, atuantes nas distintas cidades do país, que Martinell considera os "portadores dos murmúrios cotidianos". Atuam onde muitas vezes o Estado não tem olhos nem ouvidos e carregam consigo toda a potência de ativação da cultura nos diversos territórios. Criam ações que repercutem na economia, educação, e desenvolvimento social de distintos territórios brasileiros. Para isso, é preciso um processo de escuta sensível e atento, feito em muitas vias e vozes. Estimular a interação e sinergia 
dos agentes culturais de um determinado campo ou território e compreender suas distintas demandas e configurações exige mudança em nossa tradição política enrijecida que não favorece uma perspectiva de protagonismo, empoderamento e autonomia aos distintos atores sociais.

Para que esse processo se amplie e se consolide, destacamos como fundamentais alguns fatores. O reconhecimento da importância de que os agentes, culturais são um elemento essencial às dinâmicas culturais, sejam eles artistas, militantes, produtores, mobilizadores ou gestores, não só por serem portadores dos anseios históricos, mas também por sua capacidade de apontar novos caminhos. Muitas vezes agem onde o Estado não chega e com suas ações, dão materialidade às políticas e programas. Em outras, apontam novas rotas e criam realidades improváveis. Por sua diversidade e capilaridade territorial, trazem importantes contribuições e perspectivas à gestão pública. Por tudo isso, defendemos como premissa básica que não se faz política cultural e gestão democrática para os agentes, e sim com os agentes.

Para essa vitalidade cultural nas cidades, precisamos reconhecer ainda que as políticas culturais se dão em conjunto de forças, algumas vezes convergentes e em outras não, mas sempre em processos de tensão e disputa. Portanto, faz parte da atividade da gestão e da produção cultural, o exercício da conciliação, da negociação e esforços de mediação entre distintos atores e expectativas.

Ao nos relacionarmos com as múltiplas territorialidades e as diferentes perspectivas dos agentes culturais, compreendendo as tensões como processos de construção e compartilhamento, estamos estimulando a potência e a vitalidade do campo cultural. Vitalidade que contempla distintas interações e trocas; anima e acolhe novos conhecimentos e caminhos; possibilita a participação da sociedade, de forma a dinamizar a energia que anima e enriquece a tessitura social. Vitalidade como sinônimo de potência criativa.

E são esses distintos agentes atuando nas diversas cidades brasileiras, em uma relação de reconhecimento mútuo, vitalidade e tensão, que possibilitarão o surgimento de uma nova forma de ativação da cultura no país. Deslocando centros de poder, realizando potentes microrrevoluções, descentralizando espaços, formando artistas e técnicos, estimulando novos públicos e gerando economia e desenvolvimento social. Só com cultura e arte construiremos novas cidades.

Com o Estado e para além do Estado, precisamos construir uma política criativa que não seja engessada pelo aparato burocrático, que se mostre dinâmica e orgânica, possibilite novas éticas, promova outras formas de criação e interação social e outros cenários para a cultura nas cidades. Uma cultura plural, descentralizada espacial e socialmente, com novos atores e múltiplas linguagens, onde possamos criar e produzir mais livremente e voltar a trabalhar de forma compartilhada em um lócus territorial, interagindo com a multiplicidade de pessoas, cidades, bairros e empresariado local.

Criar e ampliar mercados. Buscar novas formas de sustentabilidade e desenvolver tecnologias de financiamento e produção cultural colaborativa, criando projetos que façam sentido para suas comunidades, onde as pessoas possam se sentir envolvidas de alguma forma. Investir na formação de públicos e consumidores de cultura e desconcentrar a oferta cultural nas cidades. Buscar formas de mobilizar pessoas para projetos que conciliem qualidade estética e liberdade artística. Atinar para o fato de que nem sempre os processos de democratização da cultura 
passam pela gratuidade obrigatória e pela cobrança de ingressos (ainda que com valores simbólicos), mas muito mais por fatores relacionados à educação, à oferta de produtos artísticos e culturais continuada, descentralizada, ampla e plural; ou seja, a um valor a esse bem atribuído.

É preciso também não permitir que o Estado recue em suas funções de garantir as políticas e assegurar os direitos culturais, mas também buscar formas de (co)existir para além do Estado. Romper um ciclo antigo e oscilante de dependência e ressentimentos. Aprender a atuar politicamente, de forma propositiva, afetiva e coletiva. Dessa forma, segundo Barbalho (2016), faz-se necessária uma política cultural que desloque os campos do sensível, que possibilite a vista das manifestações e movimentos culturais antes encobertos, a escuta de discursos onde antes só se ouviam barulhos e que sejam inventadas questões que antes não existiam.

Cidades precisam de vitalidade e proximidade, efetivadas por meio de uma política cultural que, segundo Lúcia Maciel (2008, p. 77):

só pode ser pensada hoje enquanto ação coletiva, criada e implementada com a participação ativa dos indivíduos, sem o que não faz mais sentido. Proximidade torna-se a palavra chave para designar as políticas culturais: quanto mais perto dos indivíduos, mais viável se torna sua participação, refletindo os desejos daqueles que dela se beneficiarão.

Esses são alguns dos desafios que estão postos e, para eles, não há caminho fácil. Uma das primeiras tarefas consiste em criar condições e oportunidades de aproximar arte e cultura da vida cotidiana das pessoas, onde quer que estejam, de forma a gerar nelas a sensação de pertencimento, encantamento e identificação.
Cultura e arte passariam assim a não ser "assunto" exclusivo de artistas, produtores e Estado, mas de pessoas comuns, que sonham, habitam e labutam nas cidades. Teixeira Coelho (2017) aponta um caminho possível ao afirmar que "o microcultural é a mola, a semente, o estopim”. É na vida vivida, nas rotas de fugas e enfrentamentos cotidianos que se fará uma política criativa.

Como estopins dispersos em todas as cidades, os agentes culturais carregam consigo uma potência de ativação territorial capaz de provocar fissuras na institucionalidade da cultura por meio de guerriIhas, disputas e tensões. Em sua potência de vida e desejos, trazem uma nova perspectiva à cultura no país. Onde impera o discurso do deserto, há muita vida pulsando. O novo já está acontecendo. Perceber e acolher esse movimento são tarefas que nos cabem, e é também o convite que Fabiano dos Santos ${ }^{\mathrm{IX}}$, poeta e Secretário da Cultura do Ceará nos faz:

Precisamos mobilizar as pessoas e animar as cidades. Animá-las no sentido de alma mesmo - ânima - e de espírito. E quem insufla as almas e espíritos de uma cidade? Respondo: as artes e a cultura com seus saberes, estéticas e experiências. Sem alma não há habitantes. Precisamos habitar de almas nossos habitantes com repertórios e percursos culturais. Arrepiar as pessoas por entre as veredas da cidade! Arrepios capazes de mobilizar as pessoas e animar as cidades através das artes... Travessia. Porque, em primeira análise estamos falando mesmo é do direito à cidade como o direito de reinventá-la em outra cidade. Mais humanista e solidária. De reinventá-la por meio de movimentos de afetos, mas também de bravuras; de experiências de delicadezas, mas também de forças; de mobilidades de existências, mas 
também de resistências; de fluxos espontâneos, mas também de sustentabilidades. Dinâmicas necessárias para construção de novos convívios sociais e de novas zonas de contatos e tatos culturais que só as artes permitem movimentar em prol de uma cidade com convivências mais justas e bonitas... pensando na Microfísica do Poder de Michel Foucault... fui tomado por substantivos compostos do tipo micro práticas, micro feixes, micro relações, micro cruzamentos, micro Malhas, micro redes, micro teias, micro-ondas culturais que podemos gerar numa espécie de cultura bacteriana de artes que pode tomar conta das cidades. Microrganismos que para serem vistos não necessitam exatamente de microscópios privados ou estatais, mas, talvez, de caleidoscópios que podem gerar combinações a partir de luzes e olhares diversos numa cartografia poética da cidade.

Nos inspiramos também em um convite de Michel Maffesoli (2011), que incita a perceber novas potências, compreender atualizações, estar permeável a pequenas mudanças e às formas diversas que estas assumem, captando o que ele nomeia de ruído do fundo do mundo. A metáfora do som do fundo do mundo remete a uma escuta atenta e sensível; a uma postura não temerosa, a coragem de enxergar o que ainda não está posto; a busca por novos sinais e espaços, ou, como ele diz, por aquilo que está "em vias de aparecer no céu de nossa sociedade" (MAFFESOLI, 2011, p. 23). Para isso, o autor apresenta caminhos que podem auxiliar essa escuta sensível do novo. Segundo ele, "é preciso ver bem para trás, para poder ver muito à frente" (idem). E foi assim que ao mirar um passado recente das políticas culturais no Brasil, vislumbramos um novo que já está acontecendo.
Nessa perspectiva, Maffesoli apresenta pistas para onde devemos direcionar o olhar ao evocar vinculações territoriais, sensibilidades ecológicas, a valorização de produtos da terra, a estética e o instante presente. Aponta ainda a tendência ao envolvimento, em contraposição ao desenvolvimento, destacando uma visão mais sensível e qualitativa, necessária para a compreensão do que denomina de muda pós-moderna.

Eis o processo de muda em que nos encontramos. Está chegando o tempo onde "não se pode mais negar a importância do poder espiritual, o retorno vigoroso da cultura, o prevalecimento do imaterial, a presença do invisível" (idem, p.29). Evocamos também a necessidade de uma institucionalidade cultural mais sensível que possibilite, segundo Morin e Teixeira (COELHO, 2017), a expressão poética da vida e a arte como companheira de viagem. Ter nas cidades campos férteis onde os agentes culturais possam atuar incansavelmente arando as terras de um Brasil profundo, rico e diverso.

\section{Bibliografia}

BARBALHO, Alexandre. Política cultural e desentendimento. Fortaleza: IBDCult, 2016.

BARBALHO, Alexandre; BEZERRA, Jocastra; GADELHA, Rachel. Políticas Públicas de Cultura no Governo Lula e Governamentalidade: a Cultura como dispositivo de controle. Artigo apresentado no XVI Congresso Brasileiro de Sociologia. Salvador, 2013.

CERTEAU, Michel de. A Cultura no Plural. Campinas: Papirus, 2012.

COELHO, Teixeira. A Cultura e seu contrário: cultura, arte e política pós 2001. São Paulo: lluminuras, Itaú Cultural, 2008a. 
COELHO, Teixeira. Microcultura, cultura subjetivada, a arte e a vida. Documento de uso interno do Curso de Especialização em Gestão e Políticas Culturais. Itaú Cultural e Universidad de Girona. 2017a.

COELHO, Teixeira. Posfácio para a turma 2016/2017. Documento de uso interno do Curso de Especialização em Gestão e Políticas Culturais. Itaú Cultural e Universidad de Girona. 2017b.

COELHO, Teixeira (org.). A cultura pela cidade. São Paulo. Iluminuras, Itaú Cultural, 2008b.

FOUCAULT, Michel. A microfísica do poder. Rio de Janeiro: Graal, 1984.

MACIEL, Lúcia. A Cidade como experimentação. Revista Observatório Itaú Cultural, n. 5, São Paulo, 2008.

MACIEL, Lúcia. A Nova Institucionalidade da Cultura. Documento de uso interno do Curso de Especialização em Gestão e Políticas Culturais. Itaú Cultural e Universidad de Girona. 2017.

MAFFESOLI, Michel. A Saturação. São Paulo: Iluminuras , Itaú Cultural, 2011.

MARTINELL, Alfons. Los Agentes Culturales. Documento de uso interno do Curso de Especialização em Gestão e Políticas Culturais. Itaú Cultural e Universidad de Girona. 2017a.

MARTINELL, Alfons. Reflexões prévias sobre a Institucionalidade cultural. Documento de uso interno do Curso de Especialização em Gestão e Políticas Culturais. Itaú Cultural e Universidad de Girona. 2017b.

YÚDICE, George. A conveniência da cultura: usos da cultura na era global. Belo Horizonte: UFMG, 2004.
I Rachel de Souza Gadelha Costa. Graduada em Antropologia pela Unicamp e Mestre em Políticas Públicas e Sociedade pela Universidade Estadual do Ceará. Possui curso de pós-graduação em Administração e Gestão Cultural pela Universidade de Barcelona e Gestão e Políticas Culturais pelo Itaú Cultural e Universidade de Girona. Gestora cultural na Secretaria da Cultura do Estado do Ceará. Contato: rachelgadelha@gmail.com

II Lei $n^{\circ} 7.505$, de dois de julho de 1986, conhecida como Lei Sarney e Lei $n^{\circ} 8.313$ do dia 23 de dezembro de 1991, denominada popularmente como Lei Rouanet.

III Discurso proferido em 02/01/ 2003. Disponível em http://ovinocaprinocultura/discursos/-/as set_publisher/DmSRak0YtQfY/content/discurso-do-ministro-Gilberto-gil-na-solenidade-de-transmissao-do-cargo-35324/10883

IV Instrumentos de seleção para escolha de projetos a serem financiados pelo poder público, direcionados a segmentos culturais e sociais estabelecidos como prioritários pelo Estado.

V Em 31 de agosto de 2016.

VI Instrução Normativa n 1, de 20 de março de 2017.

VII Conjunto de leis, normas e estruturas administrativas ou como um aglomerado de organizações, equipamentos e serviços que uma comunidade, ou melhor, um país, tem criado ao longo da sua história. (MARTINELL, 2017b, p.1).

VIII Exposição realizada no Centro Cultural Santander, em Curitiba, em setembro de 2017. Fechada um mês antes do previsto depois de intensos protestos de grupos religiosos e do MBL (Movimento Brasil Livre) por ter seu conteúdo considerado nocivo à sociedade.

IX Depoimento feito nas redes sociais - facebook pessoal em 15 de novembro de 2016. 